\title{
HOW AND WHY DO SOCCER COACHES USE SMALL-SIDED GAMES IN THE TRAINING PROCESS?
}

original paper

doi: https://doi.org/10.5114/hm.2017.73624

\author{
GONÇALO ALVES ${ }^{1}$, FILIPE MANUEL CLEMENTE ${ }^{2,3}$, PAULO MALICO SOUSA ${ }^{1}$, \\ VÁLTER PINHEIRO ${ }^{1}$, FERNANDO JORGE LOURENÇO DOS SANTOS ${ }^{4}$ \\ ${ }^{1}$ Institute of Educational Sciences, Lisbon, Portugal \\ ${ }^{2}$ School of Sport and Leisure, Polytechnic Institute of Viana do Castelo, Melgaço, Portugal \\ ${ }^{3}$ Instituto de Telecomunicações, Delegação da Covilhã, Covilhã, Portugal \\ ${ }^{4}$ School of Education, Polytechnic Institute of Setúbal, Setúbal, Portugal
}

\begin{abstract}
Purpose. The small-sided games (SSGs) allow to work in specificity, in accordance with the characteristics of the soccer game, the physical, technical, tactical, and psychological aspects. This study intends to understand how and why coaches use the SSGs in the training process.

Methods. For this purpose, we applied a semi-structured interview. Two coaches were interviewed owing to their vast experience in high-performance training and youth training. The analysis was carried out through content analysis. We used categorization to group data with common characteristics. The category system was defined later.

Results. The results demonstrate that SSGs are an integral part of the training process, allowing work in the physical, technical, and tactical aspects. The coaches interviewed argue that SSGs are an important work strategy for the articulation of the players in the sector and inter-sector of the team, on the basis of the tactical principles that they see reproduced in the competition.

Conclusions. According to the interviewed coaches, SSGs are relevant as they may develop both tactical principles and physical capabilities. Applying such games during all the season allows to establish a direct relationship with specific moments that occur in official competitions.
\end{abstract}

Key words: training, soccer, small-sided games

\section{INTRODUCTION}

Soccer is characterized by complexity, variability, and unpredictability [1,2]. The performance of the players and the team is a result of the training process, once it prepares them for the complex and dynamic requirements of the competition [3]. This competitive reality can be reproduced in training sessions by using specific tasks that aim at the possibility of interactions and increase the frequency of technical actions and decision making $[4,5]$. The use of specific exercises in the training session improves individual and the team's collective performance [6]. Therefore, training exercises should stimulate perception-action cycles [7], as characteristic of the competition context, through manipulating practice areas (e.g., field width and length) and game objectives and rules (task conditions) [8, 9]. Applying small-sided games (SSGs) allows to coordinate players at different moments of the game and promote tactical principles that guide the playing style of the team $[10,11]$.

However, for optimum performance of the players and the team it is necessary to maximize the technical, tactical, psychological, and physical factors [4, 12]. SSGs may replicate specific dynamics that occurs in an official match, mainly considering network relationships and the specific effort regimens [13-15]. However, SSGs can be managed in different ways, depending on the

Correspondence address: Fernando Jorge Lourenço dos Santos, Instituto Politécnico de Setúbal - Escola Superior de Educação, Campus do Instituto Politécnico de Setúbal, Estefanilha, 2914-504 Setúbal, Portugal, e-mail: fjlsantos@gmail.com

Received: November 29, 2017

Acepted for publication: January 31, 2018

Citation: Alves G, Clemente FM, Sousa PM, Pinheiro V, Dos Santos FJL. How and why do soccer coaches use small-sided games in the training process? 2017;18(5)special/issue:117-124; doi: https://doi.org/10.5114/hm.2017.73624. 
G. Alves, F.M. Clemente, P.M. Sousa, V. Pinheiro, F.J.L. Dos Santos, Small-sided games in the training process

ultimate goal of the coach [10]. Specific task conditions (size of field, number of players, use of goalkeepers, modification of rules), training regimen (continuous or intermittent), or existence of verbal encouragement promote different responses in terms of physiological and physical load, technical skills, tactics, and decision making [13, 16, 17].

The purpose of this study was to use qualitative methodology to understand how and why coaches apply SSGs in the training process. Through a qualitative approach, Clemente et al. [18] also sought to recognize how coaches use their knowledge to develop SSGs. Our aim, through the interview, was to analyse the coaches' perception of SSGs and their opinions about the implications of such games for the soccer training context [19].

\section{MATERIAL AND METHODS}

\section{Participants}

The coaches participating in the research represent extensive training experience. Coach 1 has Level 3 (UEFA A License) experience in high performance in senior teams and coach 2 has Level 2 (UEFA B License) training experience in young soccer top clubs. Both have developed their work in Portuguese clubs for over 10 years. The study followed the standards for research in humans in accordance with the Declaration of Helsinki [20].

\section{Instruments}

The information about the coaches' perception of the use of SSGs in the training process was collected through a semi-structured interview with 12 questions (Table 1). The instrument allows to understand and interpret (how and why) the way coaches develop their professional activity [21], specifically in the use of SSGs in the training process.

The interview was submitted to a validation process with the consideration of the procedures defined by Purdy [21] and Milistetd et al. [22] for the validity of construction and content. The questions of the investigation interview were created on the basis of the specific literature on SSGs. Later validation was carried out by a group of experts linked to the investigation into the SSGs and training of young and senior players. After some recommended corrections, the experts stated that the questions met the purpose of the study.

\section{Procedures}

The present study design and objectives were presented to the coaches. After their acceptance to participate in the investigation, the interviews were carried out, with a duration of ca. 30 minutes. The interviews were recorded through a mobile phone sound pickup and later transcribed in full to the word processor of Microsoft Word. According to Morse and McEvoy [23], interviews that are carried out in a face-to-face and individual way are the most valid form of data collection. The interviews were then returned to the coaches for validation. The transcript was considered concordant with what had been said. With these procedures, we intended to guarantee the descriptive validity (registration of the interview with exactness) and interpretative validity (confirmation of the interview transcription by the participants) of the investigation [24].

Table 1. List of questions in the applied interview

1. How important is it to use SSGs in the training unit?

2. What is the relevance of SSGs in the implementation of a game or training model?

3. What are the key benefits of SSGs for you and for your athletes?

4. What are the main limitations that SSGs impose on you and on your athletes?

5. In your view, do athletes in a training situation have a greater preference for SSGs or formal game conditions?

6. What dimension do you prefer (technical, tactical, physical) in the use of SSGs?

7. When thinking about the development of physical skills, do you prefer analytical training or SSG forms?

8. What are the constraints that you find most relevant in the construction of SSGs in order to achieve the objectives related to the tactical dimension?

9. What are the conditions that favour the construction of SSGs?

10. At what point in the training unit do you use SSGs? And in what trainings of your microcycle?

11. Is the use of SSGs homogeneous throughout the microcycles of the sports season or does it assume greater preponderance in specific phases?

12. To what extent do you think athletes make a transfer between the SSGs and the competitive game situation? 
Data analysis

The data underwent content analysis [25]. The categorical technique was used, and the information provided by the coaches with common characteristics was grouped in categories defined later [26, 27]. The categorization process was performed manually [18]. The inter-coder reliability was analysed by dividing the agreements on the combination of agreements and disagreements, with acceptable values being recorded (> 80\%) [28].

\section{Ethical approval}

The research related to human use has been complied with all the relevant national regulations, institutional policies and in accordance the tenets of the Helsinki Declaration, and has been approved by the authors' institutional review board or equivalent committee.

\section{RESULTS AND DISCUSSION}

The results are relative to the coach with experience in high-performance senior soccer (coach 1) and the coach with experience in coaching young people at top clubs (coach 2). The information collected from the interviews was divided into four categories: (1) relevance of SSGs; (2) construction of SSGs; (3) SSGs and training periodization; (4) SSGs vs. competition (Table 2).

\section{Relevance of SSGs}

The interviewed coaches report great relevance that SSGs have in high-performance soccer and youth training.

'It's the thing I always have to do in my training, I attach a lot of importance to the repetition of the execution of technical gestures: these games force you to think fast, there is more mobility, more tactical reading, and consequently more intensity' (coach 1).

'The SSGs are very important, I would say essential in my training process, they allow me to work the important aspects of the game in a micro way, in high intensity regimes. I can improve the performance of the athletes' (coach 2).

The use of SSGs and counterpoint with more traditional methodologies is to some degree controversial among coaches [29-32]. The new training methods aim to develop simultaneously the physical, technical, and tactical psychological aspects through a practice that is more ecological and contextualized with the char- acteristics of the competition [33-35]. According to the ecological dynamics, intentional behaviour and decision making result from the interaction between the players and the competitive context, influenced by the information coming from the competition [9, 36, 37].

Regarding the relevance of SSGs, the interviewed coaches add that this training strategy is important for implementing the team's game model, not forgetting the physical demands of the sport.

'For the implementation of your game model, the reduced games are decisive because if you have dynamic and intense players in your game, you can take advantage of the use of games to evolve your model' (coach 1).

'With the accomplishment of the reduced games, I can work my model of game, with intensity, correcting and working the situations that I intend, always aiming to boost the abilities of athletes' (coach 2).

The SSGs allow, through the manipulation of the conditioners of the exercise, to work the coordinated interaction between the players in the different moments of the game, considering the tactical principles of the team [10,38].

One of the issues raised in the coaches' discussion about the use of SSGs is realigned with their intensity. The coaches reveal that through SSGs, they can adapt the intensity to the characteristics of the competitive context. Although there are authors who point out that one of the limitations of SSGs is that they cannot guarantee the level of intensity required in the competitive context $[14,15]$, researchers indicate that correct manipulation of the games (size of the field, number of players, use of goalkeepers, modification of rules) allows the adaptation of the intensity to the competitive requirements, to achieve objectives of physiological stimulation for the development of the players [5, 13, 39], and, simultaneously, to work the technical and tactical aspects, as well as decision making $[8,15]$. Another relevant question regarding the physiological response of the players is the existence or absence of encouragement. The external motivation resulting from the coach's supervision can increase the athlete's acute response [13, 15, 16].

Still on the relevance of the SSGs, the coaches mention that they evaluate the implementation of the coach's ideas as well as work aspects as essential to the game.

'It allows me to make sense if my ideas are well interpreted by the players. Here in these games, the athletes are able to work out aspects that are useful to them in the game, in an intense way and close to the rhythms adopted in the game' (coach 1).

'[...] decision-making ability, constant mobility, a lot of intensity and dynamics' (coach 2). 


\section{HUMAN MOVEMENT}

G. Alves, F.M. Clemente, P.M. Sousa, V. Pinheiro, F.J.L. Dos Santos, Small-sided games in the training process

Table 2. Qualitative data on how and why coaches use SSGs

Categories Interview statements

'It's the thing I always have to do in my training, I attach a lot of importance to the repetition of the execution of technical gestures: these games force you to think fast, there is more mobility, more tactical reading, and consequently more intensity' (coach 1)

'The SSGs are very important, I would say essential in my training process, they allow me to work the important aspects of the game in a micro way, in high intensity regimes.

I can improve the performance of the athletes' (coach 2)

'For the implementation of your game model, the reduced games are decisive because if you have dynamic and intense players in your game, you can take advantage of the use of games to evolve your model' (coach 1)

'With the accomplishment of the reduced games, I can work my model of game, with intensity, correcting and working the situations that I intend, always aiming to boost the abilities of athletes' (coach 2)

Relevance of SSGs 'It allows me to make sense if my ideas are well interpreted by the players. Here in these games, the athletes are able to work out aspects that are useful to them in the game, in an intense way and close to the rhythms adopted in the game' (coach 1)

'[...] decision-making ability, constant mobility, a lot of intensity and dynamics' (coach 2)

'The coach cannot only plan small games, he must give dimension to the team, he must have sensitivity' (coach 1)

'The criterion of the conditioners that are placed in the exercises, so that there is no risk that the objective of the exercise is lost owing to excessive complexity. It is essential to be aware of the level of athletes I have and the competitive reality' (coach 2)

'My intention is to give priority to all dimensions' (coach 2)

'The technical and physical dimension are more present in games without goal. The tactical dimension is more present in games with goal' (coach 1)

'I give importance to all; if you want more intensity, you will have to reduce space, pay attention to the number of players, but the one that gives more importance is the number of touches Construction of SSGs in the ball' (coach 1)

'[...] it depends on the number of players and the space, I look at the tactical issues to work on' (coach 2)

SSGs and training '[...] I apply from the first day of the pre-season until the end of the season [...]' (coach 2) periodization

'[...] players become more dynamic. If the coach applies SSGs in exaggeration, he runs the risk of lack of dimension of the game; otherwise the transfer is great' (coach 1) 'I think the transfer is done in a natural way, it always depends on what you work and how SSGs vs. competition you work the situations of reduced and conditioned game. Players will have the chance to be confronted with countless situations, and they will have to give the answer and thus develop their abilities. This will be reflected in the quality of the athletes, so the quality of the game will increase' (coach 2)

SSG - small-sided game

In this perspective, it is important for the coach to have a good knowledge of the game to master the main constraints that influence the behaviour in competition and give him the competence to create contexts that allow players to understand, experiment, explore their possibilities in relation to the ball, free space, companions and opponents, as well as make effective decisions $[10,36,40]$.
Regarding the main aspects that need attention in the use of SSGs, the coaches refer to the questions concerning the complexity and level of the athletes, as well as the importance for the players and team not to lose the notion of team size (width and depth) vs. playing space in the competition.

'The coach cannot only plan small games, he must give dimension to the team, he must have sensitivity' (coach 1). 
'The criterion of the conditioners that are placed in the exercises, so that there is no risk that the objective of the exercise is lost owing to excessive complexity. It is essential to be aware of the level of athletes I have and the competitive reality' (coach 2).

As for the training factors that coaches most favour in SSGs, coach 2 refers to the control of physical, technical, tactical, and psychological aspects.

'My intention is to give priority to all dimensions.'

However, coach 1 mentions an important issue regarding the objectives of the exercise and the potential use of goal.

'The technical and physical dimension are more present in games without goal. The tactical dimension is more present in games with goal.'

The question of the potential use of goalkeepers in the SSGs, indicated by coach 1 , has an influence on the intensity of the exercise [15, 16, 41]. In SSGs with the use of goalkeepers, players in the defensive process have a greater concern in the defence of their goal, and in the offensive process they perform the attack at the opponent's goal more safely [13, 16], which is further promoted in the tactical aspects of the game.

\section{Construction of SSGs}

Regarding the construction of SSGs, the coaches interviewed warn of some conditioning factors they have in mind.

'I give importance to all; if you want more intensity, you will have to reduce space, pay attention to the number of players, but the one that gives more importance is the number of touches in the ball' (coach 1).

'[...] it depends on the number of players and the space, I look at the tactical issues to work on' (coach 2).

In the construction of SSGs, the coaches manipulate the conditions of the field size, the number of players, the use of goalkeepers, and the modification of rules and training regime to achieve specific objectives of training $[15,16]$. According to Clemente et al. [13], there are constraints that can be considered in the construction of SSGs (dimensions of goals, definition of specific zones, limitation of the number of touches in the ball) to work the physical, technical, and tactical aspects.

The size of the field should be considered in the construction of SSGs as it influences the game intensity and the motor response of the players. Larger fields increase the intensity of exercise, as opposed to smaller fields. However, the size of the field and the time of the exercise should be determined by the type of goal that the trainer intends to achieve [42].

The tactical work is increased by manipulating the size and shape of the field, introducing additional players, and using float players in the side corridors $[6,11,43]$. More specific technical skills occur with the increase of the number of players [44]; however, a smaller number of players allows a more effective technical training [16]. SSGs with fewer players promote increased exercise intensity [13, 45]. Katis and Kellis [5] report that $3 \times 3$ SSGs favour physical and technical work, while $6 \times 6$ ones are better for tactical development.

In the construction of SSGs, the modification of the rules allows to create constraints to stimulate the physical, technical, and tactical aspects $[4,15]$. Modifying the directionality of the game influences the intensity of the exercise. When the objective is to maintain possession of the ball or to finish in mini-goals, the exercise is more intense than SSGs with the use of goalkeepers. The use of mini-goals is a good strategy for the coach to work tactically without losing intensity [38]. As for the number of touches on the ball, the intensity of the exercise also plays a role. Touches limitation increases exercise intensity compared with the number of free touches [12].

\section{SSGs and training periodization}

With reference to the periodization of training and the use of SSGs, the interviewed coaches agree with what was mentioned by coach 2 :

'[...] I apply from the first day of the pre-season until the end of the season [...].'

Training periodization, considering SSGs, allows the development of the physical capacities and, concomitantly, the technical and tactical aspects [46].

Clemente et al. [13] present a proposal of training periodization with the use of SSGs. The authors note that in the pre-season, coaches should plan low levels of intensity, promoting aerobic work through $6 \times 6,7 \times 7$, and $8 \times 8$ games. As the competitive period approaches, high-intensity aerobic work gains importance through $3 \times 3$ and $4 \times 4$ games. During the season, aerobic work maintains, and anaerobic work gains relevance in schemes of intermittent effort.

\section{SSGs vs. competition}

Regarding the transfer between the application of SSGs and the competition, the coaches indicate:

'[...] players become more dynamic. If the coach applies SSGs in exaggeration, he runs the risk of lack of dimension of the game; otherwise the transfer is great' (coach 1). 
G. Alves, F.M. Clemente, P.M. Sousa, V. Pinheiro, F.J.L. Dos Santos, Small-sided games in the training process

'I think the transfer is done in a natural way, it always depends on what you work and how you work the situations of reduced and conditioned game. Players will have the chance to be confronted with countless situations, and they will have to give the answer and thus develop their abilities. This will be reflected in the quality of the athletes, so the quality of the game will increase' (coach 2).

The coaches interviewed agree that there is a tradeoff between the use of SSGs in the training process and competition. It is essential for them to construct training exercises that develop the players' understanding and ability to quickly respond to the demands of the game [33]. It is important that training recreates situations close to the competitive reality for players and team to experience them, since knowledge and memory are important in information processing [9, 40]. SSGs are an important strategy for coaches to develop individual and collective performance in solving game situations on the basis of team coordination, game moments, and tactical principles of team play $[6,10,38]$.

\section{Limitations}

One limitation that can be pointed out in our investigation is related to the number of coaches interviewed. However, unlike in quantitative research, where representative sampling questions are important to generalize the results, in qualitative research the key criterion for sample selection is not its statistical representativeness but theoretical relevance [47]. Therefore, two coaches with considerable experience in working with teams in the context of high-income seniors and young players from top clubs were interviewed. Future investigations should consider the possibility of increasing the sample of coaches interviewed in different contexts.

Also recommended for future investigations is the use of mixed methods [48] since they allow to understand how and why coaches apply the SSGs in the training process and to verify if they do it effectively or how they proceed in training.

\section{CONCLUSIONS}

The study aimed to characterize the importance of SSGs in the soccer training process. The interviewed coaches considered SSGs significant for simultaneous work in the physical, technical, and tactical dimensions. In the coaches' opinion, SSGs allow to develop individual decision making and work out the playing style of the team with the consideration of the team model. It was also reported by both coaches that SSGs allowed to transfer tactical principles to an official competition. This leads the coaches to decide to include SSGs in the planning during the periodization of the training.

\section{Disclosure statement}

No author has any financial interest or received any financial benefit from this research.

\section{Conflict of interest}

Authors state no conflict of interest.

\section{References}

1. Malta P, Travassos B. Characterization of the defenseattack transition of a soccer team [in Portuguese]. Motricidade. 2014;10(1):27-37; doi: 10.6063/motricidade.10(1).1544.

2. Clemente FM, Couceiro MS, Martins FM, Figueiredo AJ, Mendes RS. Match analysis on football: metrics to evaluate the collective behavior [in Portuguese]. Motricidade. 2014;10(1):14-26; doi: 10.6063/motricidade. 10(1).1517.

3. Sampaio J, Maçãs V. Measuring tactical behaviour in football. Int J Sports Med. 2012;33(5):395-401; doi: 10.1055/s-0031-1301320.

4. Hill-Haas SV, Coutts AJ, Dawson BT, Rowsell GJ. Timemotion characteristics and physiological responses of small-sided games in elite youth players: the influence of player number and rule changes. J Strength Cond Res. 2010;24(8):2149-2156; doi: 10.1519/JSC.0b013e3181 af5265.

5. Katis A, Kellis E. Effects of small-sided games on physical conditioning and performance in young soccer players. J Sports Sci Med. 2009;8(3):374-380. Available from: http://www.jssm.org/vol8/n3/9/v8n3-9text.php.

6. Castellano J, Frenández E, Escheazarra I, Barreira D, Garganta J. Influence of pitch length on inter- and intrateam behaviors in youth soccer. Anales Psicol. 2017; 33(3):486-496; doi: 10.6018/analesps.33.3.271051.

7. Serra-Olivares J, Garcia-Rubio J. Tactical problems, key component of the representative design of tasks within the non-linear pedagogy approach applied to sports [in Spanish]. Retos. 2017;32:270-278.

8. Davids K, Araújo D, Correia V, Vilar L. How small-sided and conditioned games enhance acquisition of movement and decision-making skills. Exerc Sport Sci Rev. 2013;41(3):154-161; doi: 10.1097/JES.0b013e318292f3ec.

9. Seifert L, Davids K. Ecological dynamics: a theoretical framework for understanding sport performance, physical education and physical activity. In: Bourgine P, Collet P, Parrend P (eds.), First Complex Systems Digital Campus World E-Conference 2015. Cham: Springer; 2017; 29-40. 
10. Delgado-Bordonau JL, Mendez-Villanueva A. Tactical periodization: Mourinho's best-kept secret? Soccer Journal. 2012;29-34.

11. Padilha MB, Guilherme J, Serra-Olivares J, Roca A, Teoldo I. The influence of floaters on players' tactical behaviour in small-sided and conditioned soccer games. Int J Perform Anal Sport. 2017;17(5):721-736; doi: 10.1080/24748668.2017.1390723.

12. Dellal A, Hill-Haas S, Lago-Peñas C, Chamari K. Smallsided games in soccer: amateur vs. professional players' physiological responses, physical, and technical activities. J Strength Cond Res. 2011;25(9):2371-2381; doi: 10.1519/JSC.0b013e3181fb4296.

13. Clemente FM, Martins FM, Mendes RS. Periodization based on small-sided soccer games: theoretical considerations. Strength Cond J. 2014;36(5):34-43; doi: 10.1519/ SSC.0000000000000067. Available from: https:// journals.lww.com/nsca-scj/Fulltext/2014/10000/Periodization_Based_on_Small_Sided_Soccer_ Games_.4.aspx.

14. Gabbett TJ, Mulvey MJ. Time-motion analysis of smallsided training games and competition in elite women soccer players. J Strength Cond Res. 2008;22(2):543552; doi: 10.1519/JSC.0b013e3181635597.

15. Hill-Haas SV, Dawson B, Impellizzeri FM, Coutts AJ. Physiology of small-sided games training in football: a systematic review. Sports Med. 2011;41(3):199-220; doi: 10.2165/11539740-000000000-00000.

16. Aguiar M, Botelho G, Lago C, Maças V, Sampaio J. A review on the effects of soccer small-sided games. J Hum Kinet. 2012;33:103-113; doi: 10.2478/v10078-0120049-x.

17. Pasquarelli BN, Souza VAFA, Stanganelli LCR. The small-sided games in soccer [in Portuguese]. Rev Bras Futebol. 2010;3(2):2-27.

18. Clemente FM, Martins FML, Mendes RS. How coaches use their knowledge to develop small-sided games: a case study. S Afr J Res Sport Phys Educ Recr. 2015; 37(1):1-11.

19. Agee J. Developing qualitative research questions: a reflective process. Int J Qual Stud Educ. 2009;22(4): 431-447; doi: 10.1080/09518390902736512.

20. Harriss DJ, Atkinson G. Ethical standards in sport and exercise science research: 2014 update. Int J Sports Med. 2013;34(12):1025-1028; doi:10.1055/s-0033-1358756.

21. Purdy L. Interviews. In: Nelson L, Groom R, Potrac P (eds.), Research methods in sports coaching. London: Routledge; 2014; 162-170.

22. Milistetd M, Mesquita I, Nascimento J, Sobrinho A. Coaches' conceptions about competition role on the sport development of youth volleyball players [in Portuguese]. R. da Educação Física. 2008;19(2):151-158.

23. Morse A, McEvoy CD. Qualitative research in sport management: case study as a methodological approach. Qual Rep. 2014;19(31):1-13. Available from: http:// nsuworks.nova.edu/tqr/vol19/iss31/3.
24. Maxwell JA. Understanding and validity in qualitative research. Harvard Educ Rev. 1992;62(3):279-300; doi: 10.17763/haer.62.3.8323320856251826.

25. Bengtsson M. How to plan and perform a qualitative study using content analysis. NursingPlus Open. 2016;2:8-14; doi: 10.1016/j.npls.2016.01.001.

26. Bardin L. Content analysis [in Portuguese]. Lisboa: Edições 70; 2008.

27. Pereira AM, Leitão JC. Research methodology in physical education and sport. Introduction to content analysis [in Portuguese]. Vila Real: Sector Editorial dos SDE; 2007.

28. Campbell JL, Quincy C, Osserman J, Pederson OK. Coding in-depth semistructured interviews: problems of unitization and intercoder reliability and agreement. Sociol Meth Res. 2013;42(3):294-320; doi: 10.1177/ 0049124113500475.

29. Ford PR, Yates I, Williams AM. An analysis of practice activities and instructional behaviours used by youth soccer coaches during practice: exploring the link between science and application. J Sports Sci. 2010;28(5): 483-495; doi: 10.1080/02640410903582750.

30. Hornig M, Aust F, Güllich A. Practice and play in the development of German top-level professional football players. Eur J Sport Sci. 2014;16(1):96-105; doi: 10.1080/17461391.2014.982204.

31. O'Connor D, Larkin P, Williams A. Observations of youth football training: how do coaches structure training sessions for player development? J Sports Sci. 2018; 36(1):39-47; doi: 10.1080/02640414.2016.1277034.

32. Partington M, Cushion C. An investigation of the practice activities and coaching behaviors of professional top-level youth soccer coaches. Scand J Med Sci Sports. 2013;23(3):374-382; doi: 10.1111/j.1600-0838.2011. 01383.x.

33. Aquino RT, Marques RR, Gonçalves LG, Vieira LH, Bedo BL, Moraes C, et al. Proposal of teaching systematization of soccer based on games: development of tactical knowledge in 10 to 11 years old players [in Portuguese]. Motricidade. 2015;11(2):115-128; doi: 10.6063/ motricidade.11(3).3724.

34. Clemente FM, Wong DP, Martins FML, Mendes R. Differences in U14 football players' performance between different small-sided conditioned games. Rev Int Cienc Deporte. 2015;11(42):376-386; doi: 10.5232/ ricyde2015.04206.

35. Lee MC, Chow JY, Komar J, Tan CW, Button C. Nonlinear pedagogy: an effective approach to cater for individual differences in learning a sports skill. PLoS One. 2014;9(8):e104744; doi: 10.1371/journal.pone.0104744.

36. Araújo D, Davids K, Hristovski R. The ecological dynamics of decision making in sport. Psychol Sport Exerc. 2006;7(6):653-676; doi:10.1016/j.psychsport.2006.07.002.

37. Santos S, Jiménez S, Sampaio J, Leite N. Effects of the Skills4Genius sports-based training program in creative behavior. PLoS One. 2017;12(2):e0172520; doi: 10.1371/journal.pone.0172520. 


\section{HUMAN MOVEMENT}

G. Alves, F.M. Clemente, P.M. Sousa, V. Pinheiro, F.J.L. Dos Santos, Small-sided games in the training process

38. Aguiar M, Gonçalves B, Botelho G, Lemmink K, Sampaio J. Footballers' movement behaviour during 2-, 3-, 4- and 5-a-side small-sided games. J Sports Sci. 2015; 33(12):1259-1266; doi: 10.1080/02640414.2015.1022571.

39. Halouani J, Chtourou H, Dellal A, Chaouachi A, Chamari K. Soccer small-sided games in young players: rule modification to induce higher physiological responses. Biol Sport. 2017;34(2):163-168; doi: 10.5114/ biolsport.2017.64590.

40. Petiot GH, Aquino R, Cardoso F, Santos R, Teoldo I. What mental process favours quality decision-making in young soccer players? Motriz. 2017;23(3):1-7; doi: 10.1590/s1980-6574201700030003.

41. Casamichana D, Castellano J, González-Morán A, García-Cueto H, García- López J. Physiological demand in small-sided games on soccer with different orientation of space [in Spanish]. Rev Int Cienc Deporte. 2011;7(23): 141-154; doi: 10.5232/ricyde2011.02306.

42. Casamichana D, Castellano J. Time-motion, heart rate, perceptual and motor behaviour demands in smallsides soccer games: effects of pitch size. J Sports Sci. 2010;28(14):1615-1623; doi: 10.1080/02640414.2010. 521168.

43. Praça GM, Folgado H, Andrade AG, Greco PJ. Influence of additional players on collective tactical behavior in small-sided soccer games. Rev Bras Cineantropom Desempenho Hum. 2016;18(1):62-71; doi: 10.5007/ 1980-0037.2016v18n1p62.

44. Sannicandro I, Cofano G. Small-sided games: analysis of the internal load and technical skills in young soccer players. Int J Sci Res. 2017;6(3):735-739; doi: 10.21275/ ATR20171583.

45. Clemente FM, Nikolaidis PT, Linden N, Silva B. Effects of small-sided soccer games on internal and external load and lower limb power: a pilot study in collegiate players. Hum Mov. 2017;18(1):50-57; doi: 10.1515/ humo-2017-0007.

46. Owen AL, Wong DP, Paul D, Dellal A. Effects of a periodized small-sided game training intervention on physical performance in elite professional soccer. J Strength Cond Res. 2012;26(10):2748-2754; doi: 10.1519/JSC. 0b013e318242d2d1.

47. Weis D, Willems H. Aggregation, validation, and generalization of qualitative data - methodological and practical research strategies illustrated by the research process of an empirically based typology. Integr Psychol Behav Sci. 2017;51(2):223-243; doi: 10.1007/s12124016-9372-4.

48. Anguera MT, Camerino O, Castañer M, Sánchez-Algarra P. Mixed methods in the investigation of physical activity and sport [in Spanish]. Rev Psicol Deporte. 2014;23(1):123-130. 